\title{
THE BRITISH NORTH GREENLAND EXPEDITION, 1952-54
}

\author{
By R. A. HAMILTON
}

Chief Scientist

$\mathrm{W}$ HEN the British North Greenland Expedition leaves for Queen Louise Land in July, it will reawaken the country's traditional naval and scientific interest in polar exploration on a scale not seen since Scott's last expedition. Travelling first by ship to Young Sound on the east coast of Greenland at $74^{\circ} \mathrm{N}$. and thence by air, it will establish its main base on the shores of a lake surveyed last summer by a small reconnaissance expedition at about lat. $77^{\circ} \mathrm{N}$., long. $24^{\circ} \mathrm{W}$. Queen Louise Land is really a series of nunataks consisting of a mountain range protruding from the inland ice which, as well as intersecting it by a number of glaciers, flows round to north and south, and isolates it from the coast, from which it is separated by two glaciers twenty miles wide which flow down the east side and meet in Dove Bay. Thus Queen Louise Land has for a long period of time been isolated from the coastal strip; but it is believed that, although during the Quaternary ice age the inland ice reached farther east than at present, the higher mountains were probably never entirely covered but remained as nunataks with their tops protruding through the ice.

In geology, the primary object is to make a thorough examination of the structure and petrology of the land forms throughout the area. Geographically, the mountain range is thought to be part of a Caledonian folding, much of which is covered by the inland ice, but which is exposed in the Franz Joseph Fjord farther south where there are two belts of younger pre-Cambrian rocks, the Eleonore Bay formation in the outer fjords and the Peterman formation in the nunataks behind the innermost fjord heads; between them a gneissic zone is encountered. It will be of special interest to study the northern continuation of what is thought to be the Peterman formation in Queen Louise Land. The investigation will consist partly of an analysis of the tectonic structures and partly of the petrology, and a study will be made of the boundaries between the gneisses and the less metamorphosed rocks. The Koch-Wegener expedition brought back a few samples from the area among which a sample of diabase was found, which indicates that igneous rocks also may well be present.

Air photographs have recently been made of the area, so the work of the surveyors will consist mainly in setting up a triangulation in Queen Louise Land and linking this to the triangulation in Germania Land on the east coast, which was mapped by the Danmark expedition. The heights above mean sealevel must, however, be measured with greater accuracy than is usual in Greenland, as one of the nunataks to the west of Queen Louise Land will be the starting-point of the line of levels to be carried across the ice-cap, and it is hoped that its height will be determined with an error of only one or two metres.

The main interest of the expedition, however, lies not so much in Queen Louise Land itself but in the northern half of the Greenland ice-cap. As soon as the expedition is safely established at its base on the shore of the lake, a sledying party will set off inland to meet an aircraft flying in from the west coast at a rendezvous at about lat. $78^{\circ} \mathrm{N}$., long. $40^{\circ} \mathrm{W}$. The aircraft will drop a hut, stores and petrol, and an
Tce-cap Station will be established which will form the base from which the parties surveying the icecap will operate and at which meteorological and glaciological work will be carried out.

The recent work of Expéditions Polaires Françaises under the leadership of Paul-Emile Victor, and theoretical work by Dr. J. F. Nye, of the Cavendish Laboratory, Cambridge (summarized in an article in Nature of March 29), have stimulated scientific interest in extensive ice-fields. From mechanical considerations, Nye derives the simple relation that the thickness of a moving ice-sheet is inversely proportional to its surface slope, irrespective of the slope of the bed of the ice-cap. This can be verified by a survey of the surface of the ice-cap and of its bed.

The ice-cap will be surveyed by two different teams of four men and three mechanical vehicles towing sledges. The gravimetric team will move slowly from the edge of the ice near the base camp, measuring the value of gravity at intervals of about four kilometres, and at times making short lateral traverses normal to the track to measure the gradient of gravity. In order to interpret the readings of the gravimeter, the height above mean sea-level at each point must be known as accurately as possible. It is necessary, then, to run a line of levels from Queen Louise Land, using either a levelling instrument or a theodolite over distances not exceeding two kilometres. This work is likely to be tedious and slow, and must be carried out with great care owing to the excessive refraction that occurs in quiet conditions on the ice-cap. When completed, however, the gravimetric survey will give an accurate profile of the ice-cap surface and a measure of its slope at all places between the ice edge and the Ice-cap Station, and from the value of $g$ and the knowledge of the thickness of the ice, measured by the seismic team, the gravity anomaly due to the underlying geological structure can be determined.

The seismic team will move more rapidly and will cover most of the northern half of the ice-cap during the first summer. Based on the Ice-cap Station, it will travel in a series of triangles and will measure the thickness of the ice sheet by seismic methods at $20-\mathrm{km}$. intervals. The heights of the ice-cap at each point will be measured by aneroid pressure, controlled by a barometric pressure at the Ice-cap Station and a 700-millibar constant-pressure chart of the Greenland area. I he seismic survey will thus give a general map of the contours of the bed of the ice-cap, while the gravimetric survey will give an accurate survey along a single traverse. It will be of greatest interest to find whether the bed of the ice-cap in the northwest is as low as $1,200-4,200$ metres below mean sea-level, as estimated by Nye. This estimate is based, however, on the existing maps giving the contours of the surface of the ice-cap, and these may well be inaccurate, as they are based only on the aneroid heights determined on the traverses of Rasmussen to the north, and of Koch and Wegener to the south, a distance of nearly $600 \mathrm{~km}$. apart. It is based, too, on the assumption that the ice sheet is moving; but, as Nye says, in the centre of a large ice sheet of considerable height, the precipitation may not be sufficiently in excess of the wastage to keep the mass moving, in which case the height 
would be determined by meteorological factors. It is possible that precipitation at this Ice-cap Station will be considerably less than at the French ice-cap station some 400 miles farther south, for the Ice-cap Station will be a greater distance from the track of depressions as they move north-eastwards along the east of Greenland and north-north-westwards up the Davis Strait.

The meteorological programme for the first year consists of the development of instruments and of micro-meteorology in conjunction with the glaciological research, which will be concerned mainly with the subject of regime. Accumulation and ablation will be measured at the Ice-cap Station and at two places on one of the marginal glaciers, one in the ablation and one in the accumulation area, where micro-meteorological stations will be set up. Accumulation will be measured at a dozen places on the glacier and at a number of places on the route to the Ice-cap Station. Accumulation in past years can be estimated by an interpretation of the profile of pits dug in the firn, and the penetration of temperature waves into the ice will be examined by temperature measurements in the ice. Ablation will be measured at intervals at several places on the glacier and on the ice-cap, and over short periods will be related to the radiation and to the vertical gradients of temperature, wind and humidity. The movement of glaciers will be studied in detail.

In order to study the propagation of radio waves across the polar regions, a programme of listening to European broadcasts over a range of frequencies at different times of day has been drawn up; further, if finances permit, soundings will be made of the ionosphere and measurements made of ionospheric winds.

The physiologist will study the acclimatization to cold by the members of the Expedition, will record variations of body temperature, especially during the Arctic night, and changes in basal metabolic rate. Experiments on nutrition, too, will be carried out.

The research programme for the second year depends on the financial position of the Expedition. The survey, and perhaps the geology, will be finished during the first year; but the glaciological programme is planned for two years, and the gravimetric survey will be continued to the west coast. 'The seismic party will finish the survey of the ice-cap by pushing farther towards Melville Bay, and an attempt will be made to investigate the nature of the rock beneath the ice-cap by refraction methods of seismic survey. Deep drilling will be attempted and, unless prevented from doing so by the plasticity of the ice, it is hoped that the depth will be reached at which the vertical temperature gradient in the ice becomes negative ; the temperature and winds in the upper atmosphere will be measured to examine the effect of the Greenland ice-cap on the general circulation.

It is a sign of the times and of the nature of modern scientific expeditions that, in order to carry out their project, the sponsors have found it necessary to build up a novel form of combined operation. In the field, the work will be purely scientific; but the scientists will be assisted by young officers from the Services, who will thus gain valuable training and experience. A combined Service and scientific enterprise of this nature offers advantages to all concerned which none of the supporting bodies could realize alone except at a much greater cost. It is hoped that this happy marriage of men of arms and science may be the pattern for future expeditions of this kind.

\section{PSYCHOLOGICAL AND PHYSIOLOGICAL ASPECTS OF FATIGUE}

$\mathrm{T}$

HE Ergonomics Research Society held a symposium on "Fatigue" at the College of Aeronautics, Cranfield, during March 24-27, at which the psychological and physiological aspects of the subject were reviewed. The 136 persons attending included representatives drawn from universities, the Armed and Civil Services, government research establishments, and private and nationalized industry. Twenty-four of the participants came from abroad.

The study of fatigue has traditionally been regarded as one of the points of close contact between physiology and experimental psychology, although it has been recognized that the problems of the two sciences in this respect are not identical and that the changes of function in peripheral organs which typify what may be called fatigue states at a physiological level are not capable of giving a direct explanation of so-called mental fatigue. Recent advances in both these sciences and in functional anatomy and industrial medicine have, as the papers in this symposium testified, preserved this contact. Manifestations of fatigue are different at different levels, but they display many common principles.

Perhaps the most important of these is that measures of the decrement of overall performance give a very incomplete picture of what happens in fatigue. Often there may be no change in overall achievement or in the adequacy of overall action; but, if detailed measures are taken of the functions which go to make up this total performance, some of them will be found to have changed markedly. The changes are, however, mutually compensatory and so keep the total performance steady. The situation is further complicated by the appearance of side-effects which may become more striking than the main effects which have produced them.

It was probably due to the recognition that the expression of fatigue is complex that fow attempts were made at precise definition. Emphasis was laid rather upon the finding of measurable criteria of fatigue and the understanding of the places that these criteria occupy in the process which is being studied. In any normal performance many mechanisms at various levels of function are involved, of which only one or two may show changes with continued exercise. It is clear, therefore, that if a full understanding of what is happening is to be obtained, measurements must be sufficiently detailed to show which mechanisms have undergone a change of function and which have remained unchanged. Such measurements must be taken during performance at the actual task concerned. It is not satisfactory to transfer the subject at intervals from this task to others designed to 'test' fatigue, because he can usually mobilize his efforts to deal adequately with a short test even when his performance at a previous long-term task has shown substantial decrement.

This general position, as it applies to psychological studies, was stated by Sir Frederic Bartlett (Cambridge) in the opening paper. He suggested that the term 'fatigue' should be used to cover all those determinable changes in the expression of an activity which can be traced to continued exercise of the activity under its normal conditions, and which lead eventually to its deterioration. For indication of 